\title{
Psychosocial factors as predictors of early onset ischemic heart disease in a sample of Pakistani women
}

Rafique, Rafia $\bowtie$

University of Punjab, Lahore, Pakistan (rafiawaqar@hotmail.com)

Amjab, Naumana

University of Punjab, Lahore, Pakistan (naumana_a@hotmail.com)

Received: 10 November 2011 Available Online: 26 January 2012
Revised: 5 January 2012 DOI: $10.5861 /$ ijrsp.2012.v1i2.62

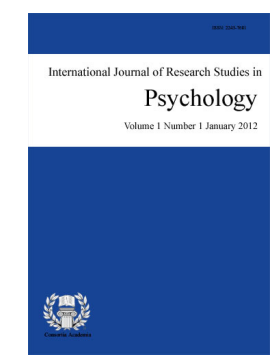

ISSN: 2243-7681 Online ISSN: 2243-769X

OPEN ACCESS

Accepted: 25 January 2012

\section{Abstract}

Empirical research documents that in some cases psychosocial factors conquer greater if not equal risk of IHD. This study was conducted to infer the psychosocial factors associated with the risk of IHD in women. Case control study design was utilized to explore the association of psychosocial factors with the risk of IHD in women aged 35 to 55 years. A sample of 71 women cases diagnosed with IHD and 142 age and gender matched community controls were recruited for this purpose. Binary logistic regression analyses was conducted to ascertain the association of proposed psychosocial factors with the risk of IHD. The values of the coefficients revealed that a unit increase in score of trait anger is associated with increase in the odds of IHD by a factor of 1.21 (95\% CI 1.04 and 1.42). A unit increase in optimism score is associated with decrease in the odds of IHD by a factor of 0.67 (95\% CI 0.53 and 0.83). The values of the coefficients reveal that each unit increase in score of social support is associated with decrease in odds of IHD by a factor of 0.91 (95\% CI 0.89 and 0.95). The study highlights that women aged 35 to 55 years are protected against the risk of IHD, and trait anger is the only risk factor of IHD. Furthermore trait anger is modifiable and can lay directions for designing preventive cardiac interventions.

Keywords: Ischemic heart disease; psychometric instruments; binary logistic regression; community controls 


\section{Psychosocial factors as predictors of early onset ischemic heart disease in a sample of Pakistani women}

\section{Introduction}

Substantial empirical evidence supports a strong association between psychosocial factors and risk of Ischemic Heart Disease (IHD). The role of stress, anxiety, depression, hostility and anger in the onset of IHD is presently confirmed through global research literature (Brotman, Golden, \& Wittstein, 2007; Krantz \& McCeney, 2002; Rosengren et al., 2004; Rozanski et al., 2005; Smith \& Ruiz, 2002; Suls \& Bunde, 2005). Studies carried out internationally highlight that besides negative psychological factors like stress, anger, hostility etc. certain positive factors namely optimism, locus of control and social support play a protective role in the onset of IHD (Kubzansky, Sparrow, Vokonas, \& Kawachi, 2001; Uchino, 2004; Wang, Mittleman, \& Orth-Gomer, 2005; Yusuf et al., 2004). Even in the presence of documented evidence that psychosocial factors in some cases determine greater if not equal risk of IHD (Kubzansky \& Kawachi, 2000; Rozanski, Blumenthal, \& Kaplan, 1999), similar proof for the Pakistani population is still lacking in this regard, especially for women population. However, to some extend the role of perceived stress, stressful life events, locus of control, anxiety and depression in explaining the onset of IHD in Pakistani population has been confirmed by Interheart study (Rosengren et a1. , 2004) that utilized 5\% of sample in their research from Pakistan. Moreover Risk corn study is the only study carried out on Pakistani population that has investigated association of psychological factors, namely stress and stressful life events with risk of IHD. Many psychosocial variables, specifically anger, hostility, social support, social dominance etc. for which ample evidence exists that they are associated with the risk of IHD from studies carried out in the Western and European countries, have never been investigated in Pakistan. This study was designed to investigate association of psychosocial factors with the risk of IHD in women.

\section{Method}

\subsection{Sample}

To infer the association of psychosocial factors with the risk of IHD, 71 women patients with confirmed diagnosis of IHD and 142 controls, those who were free of IHD before and at the time of testing were recruited. The cases recruited were patients with the first onset of IHD \{Angina and Myocardial Infarction (MI\} presenting within 24 hours of symptoms, admitted to the coronary care unit or the equivalent cardiology ward of the hospitals. Likewise two age and gender matched community controls (up to 5 years older or younger, aged 35 to 55 years) were drawn directly from special subgroups in the community who had some relationship to the cases (such as friends, neighbors' and non-blood relatives), community controls had particular characteristics like cases (age and gender), but had not yet developed the disease under investigation. We recruited cases if they had one episode of Angina with chest pain as determined by cardiologists. In addition patients with chest pain established as Angina through exercise, electrocardiography (ECG), or cardiologist's summary and symptom scores were also recruited in this study. Furthermore, patients with the first onset of acute myocardial infarction (AMI), whose diagnoses have been confirmed by the cardiologists on the basis of clinical symptoms or changes in electrocardiogram, or raised concentration of troponin levels, were included in the study.

\subsection{Inclusion/exclusion criteria}

Patients experiencing the following sign and symptoms were not included in the study sample: patients who had undergone cardiogenic shock or chest pain due to non-cardiac reasons; patients suffering from any of the significant chronic medical illness including: liver disease, hyperthyroidism or hypothyroidism, renal disease, 
Psychosocial factors as predictors of early onset ischemic heart disease in a sample of Pakistani women

malignant disease; pregnant females, as well as patients with a prior history of any psychiatric diagnosis or those who were currently on any antipsychotic medication; Patients who had a previous history of treatment for heart disease like percutaneous transluminal coronary angioplasty (PTCA) or coronary artery bypass graft (CABG) surgery; participants failing to provide informed consent (as these conditions modify the risk factors in IHD and might have an impact on behavior and lifestyle), and patients who were unable to read or write Urdu (national) language were not included in the study. Community-based controls recruited in the study were attendants, visitors or relatives of the cardiac patient, unrelated (not first-degree blood relatives) having no previous diagnosis of heart disease or history of exertional chest pain. Exclusion criteria followed for community controls was the same as that set up for the cases.

\subsection{Measures}

\subsubsection{Psychological Factors}

The Perceived Stress Scale (PSS). Cohen, Kamarck, and Mermelstein (1983) developed PSS that computes magnitude of stressful situations in one's life and the present level of experienced stress, on a 10 item scale. Each item is measured on a 5-point Likert type scale $(0=$ Never, $1=$ Almost never, $2=$ Sometimes, $3=$ Fairly often, 4 $=$ Very often). The PSS has four positively worded items $(4,5,7 \& 8)$ that are reversed scored. Internal reliability of the scale is 0.79 for our sample.

Center for Epidemiological Studies Short Depression Scale (CES-D 10). Radloff (1977) developed this 10 -item scale to measure self-reported depressive symptoms. Individuals respond to these items by relating how they felt or behaved during the past week. Items on the CES-D 10 use a 4-point Likert-type scale $(0=$ Rarely or none of the time, $1=$ Little of the time, $2=$ Occasionally and $3=$ All of the time). Two items (5 \& 8 ) are reverse scored. The scale has high reliability $(\alpha=.84)$ for our sample.

State-Trait Anxiety Inventory (STAI). Spielberger (1983) developed STAI to measure the general tendency to respond to perceived threats in the environment with anxiety. The scale has 20-items; each item is measured on a 4-point Likert-type scale ( $1=$ Not at all, $2=$ Somewhat, $3=$ Moderately, and $4=$ Very much so). There are seven items $(21,26,27,30,33,36 \& 39)$ that are reversed scored. Cronbach alpha for our sample is .78.

State-Trait Anger Expression Inventory (STAXI). Spielberger developed this inventory in (1999). It consists of 10-items that measure state and trait anger (T-Ang) on a 4-point Likert type scale $(1=$ Almost never, 2 = Sometimes, 3 = Often, and 4 = Almost always). Trait anger temperament $(\mathrm{T}-\mathrm{Ang} / \mathrm{T})$ score is obtained by composite score of four items $(16,17,18 \& 21)$ and total score on items $(19,20,22,23,24 \& 25)$ gives score of trait anger reaction (T- Ang/R). Cronbach alpha for our sample is 0.72 .

Personality Deviance Scale-Revised (PDS-R). The original scale consisted of 36 items (Bedford \& Foulds, 1978). Two subscales: Hostility and Dominance/submissiveness were employed in this study. Eight items of the hostility subscale were incorporated in the current study (Bedford \& Foulds, 1978). This hostility scale has four possible responses on each item $(4=$ Very often, 3 = Often, $2=$ Seldom, and $1=$ Never $)$. Cronbach alpha for our sample is 0.70 .

Revised Life Orientation Test (LOT-R). Scheier, Carver and Bridges (1994) authored this 10-item scale (see Appendix D) to measure generalized optimism (versus pessimism). Each item is measured on a 5-point Likert-type scale $(0=$ Strongly disagree, $1=$ Disagree, $2=$ Neutral, $3=$ Agree and $4=$ Strongly agree). The scale has four filter items $(2,5,6 \& 8)$, that measure generalized expectancies for positive versus negative outcomes and four items $(3,6,7 \& 9)$ are reversed scored. Internal reliability of the scale is $\alpha=.84$ for our sample.

Perceived Locus of Control Scale (PLCS). The perceived locus of control was assessed by the responses to six items that have been used expansively in studies conducted in Eastern Europe (Rosengren et al., 2004; Yusuf et al., 2004). Research participants were asked to which extent they agreed or disagreed with the statements. Two 
Rafique, R. \& Amjab, N.

items $(1 \& 3)$ were coded as $(0=$ Strongly disagree, $1=$ Disagree, $2=$ Neutral, $3=$ Agree and $4=$ Strongly agree $)$ and rest of the 4 items $(2,4,5, \& 6)$ were reverse scored as they were negatively worded and revealed less perceived control. The Cronbach alpha for this scale is 0.74 for our sample.

\subsubsection{Social Factors}

Monthly Income. Monthly income was assessed by family monthly income reported by the study participants in Pakistani rupees.

Education. Education was categorized as 10 or less years of formal education: it included five years of primary education; three years of middle education; and two years of secondary education. Fourteen years or less of formal education included either having an Intermediate degree or a Bachelor's degree). Sixteen or more years of formal education included a Masters degree or an equivalent degree.

To measure Dominance, a subscale of Personality Deviance Scale (PDS) comprising of 6 items (Bedford \& Foulds, 1978) with four possible responses on each item ( 4 = Very often, $3=$ Often, $2=$ Seldom, and $1=$ Never) was used. All six items were reversely scored to measure dominance, the possible score on this subscale ranges from 6 to 24 with the higher score representing greater dominance. The reliability of PDS is $\alpha=.71$ for our sample.

Multidimensional Scale of Perceived Social Support (MSPSS). Zimet, Dahlem, Zimet, and Farley (1988) authored this 12 -item, 7 point Likert-type scale $(1=$ Very strongly disagree, $2=$ Strongly disagree, $3=$ Mildly disagree, 4 = neutral, 5 = Mildly agree, $6=$ Strongly agree, and $7=$ Very strongly agree). A composite score is obtained by adding the scores on all 12 items and dividing it by 12 . Cronbach alpha for the scale is 0.72 for our sample.

\subsection{Procedure}

Approval by regulatory and ethics committee from all the five hospitals prior to initiating the research was sought by the researcher. Written consent form was prepared in Urdu and was given to participants for signature before they could take part in this study. Permission for translation and use of instruments for conducting present study was appropriately sought from authors of all the scales. To ensure a rigorous process of translation as well as to achieve equivalence between the original version and translated versions of scales, Vallerand's (1989) steps for instrument translation with slight modification were employed (see also Banville, Desrosiers, \& Genet-Volet, 2000). These steps were found to have decreased risks of errors and improved the precision of translation.

All participants were briefed about the purpose of the study and were assured about the confidentiality and privacy of their responses. Participants were told that they were free to leave the study anytime if they felt uncomfortable and that this would not incur any prejudice or penalty to them. Similar set of procedures were carried out with controls. For every case two age and gender matched community controls were recruited either that very day or at the maximum within a week. Once the participants had participated in the study the researcher thanked and debriefed the participants about the nature of the study. In case any participant asked a question pertaining to the study, the researcher answered it briefly, however if their questions required in-depth answers or understanding, they were invited by the researcher to a different time for a more detailed discussion. For this purpose the participants were given the mailing address of the researcher.

\section{Results}

\subsection{Statistical Analysis}

Unconditional binary logistic regression analyses were conducted by using the forward conditional method to infer the association of factors with risk of IHD. Multivariate odds ratios (ORs) and 95\% confidence intervals 
Psychosocial factors as predictors of early onset ischemic heart disease in a sample of Pakistani women

(CIs) for psychological factors was built, another regression model was built to ascertain association of social factors with risk of IHD. Odds ratios represented the excess risk of exposure to a factor in cases compared with controls, without exposure. In the case of binary or ordinal variables (income, education) a reference category with minimal risk was taken.

Table 1

Demographic Characteristics of Study Sample Depicted as Frequency and Percentages (\%)

\begin{tabular}{|c|c|c|}
\hline Variables & Women Cases $\quad f(\%)$ & Women Controls $\quad f(\%)$ \\
\hline \multicolumn{3}{|l|}{ Age } \\
\hline $35-40$ & $25(35.2)$ & $43(30.5)$ \\
\hline $41-45$ & $9(12.7)$ & $29(20.6)$ \\
\hline $46-50$ & $20(28.2)$ & $30(21.3)$ \\
\hline $51-50$ & $17(23.9)$ & $39(27.7)$ \\
\hline \multicolumn{3}{|l|}{ Education } \\
\hline 10 or less years & $47(66.2)$ & $66(46.8)$ \\
\hline 12 to 14 years & $23(32.4)$ & $60(42.6)$ \\
\hline 16 or more years & $1(1.4)$ & $15(10.6)$ \\
\hline \multicolumn{3}{|l|}{ Occupation } \\
\hline Business & $3(4.2)$ & $1(0.7)$ \\
\hline Government & - & $13(9.2)$ \\
\hline Private & $5(7.0)$ & $15(10.6)$ \\
\hline Self-employed & $2(2.8)$ & $4(2.8)$ \\
\hline Agriculture & - & $1(0.7)$ \\
\hline Not working & $2(2.8)$ & $1(0.7)$ \\
\hline Retired & - & - \\
\hline Housewife & $59(83.1)$ & $106(75.2)$ \\
\hline \multicolumn{3}{|l|}{ Monthly income } \\
\hline 12000 \& less & $27(38.0)$ & $25(17.7)$ \\
\hline $12000-20000$ & $24(33.8)$ & $41(29.1)$ \\
\hline 20000 to 35000 & $9(12.7)$ & $35(24.8)$ \\
\hline $35000 \&$ above & $11(15.5)$ & $40(28.4)$ \\
\hline \multicolumn{3}{|l|}{ Marital status } \\
\hline Married & $61(85.9)$ & $117(83.0)$ \\
\hline Not married & $6(8.5)$ & $11(7.8)$ \\
\hline Engaged & - & $1(0.7)$ \\
\hline Divorced & - & $1(0.7)$ \\
\hline Widowed & $4(5.6)$ & $11(7.8)$ \\
\hline \multicolumn{3}{|l|}{ Living } \\
\hline Rural & $19(26.8)$ & $36(25.5)$ \\
\hline Urban & $52(73.2)$ & $105(74.5)$ \\
\hline
\end{tabular}

Note. Monthly income is expressed in Pakistani Currency (Rupees).

Table 2

Psychological Variables Independently Associated with IHD

\begin{tabular}{|c|c|c|}
\hline Variable & $\mathrm{B}(S E)$ & $\operatorname{Exp}(\mathrm{B})$ OR $(95 \% \mathrm{CI})$ \\
\hline Step 1 & $8.59 * * *$ & \\
\hline Constant & $(2.09)$ & \\
\hline Optimism & $\begin{array}{c}-0.50 * * * \\
(0.11)\end{array}$ & $0.60(0.48-0.75)$ \\
\hline Final model & 2.34 & \\
\hline Constant & $(2.93)$ & \\
\hline Anger & $\begin{array}{l}0.19^{*} \\
(0.07)\end{array}$ & $1.21(1.04-1.42)$ \\
\hline Optimism & $\begin{array}{c}-0.40 * * * \\
(0.11)\end{array}$ & $0.67(0.53-0.83)$ \\
\hline
\end{tabular}

Note. $O R=$ odds ratio; $\mathrm{CI}=$ confidence interval. Women cases and women controls data adjusted for age. ${ }^{*} p<.05,{ }^{* * *} p<.001$ 
A Binary logistic regression analysis was performed to ascertain psychological factors associated with IHD in women by using forward conditional method, with IHD as the DV and psychological variables (Perceived stress, depression, anxiety, anger, hostility, optimism and locus of control) as predictor variables. A total of 88 women cases and controls were analyzed and the full model significantly predicted presence of IHD (Omnibus Chi-square $=49.61, d f=2, p<.001$ ). The model accounted for between $43 \%$ and $61 \%$ of variance in IHD. Overall $87.5 \%$ of the predictions were accurate. Among the psychological factors trait anger and optimism were found to be significant risk and protective predictors of IHD respectively. The values of the coefficients revealed that a unit increase in score of trait anger is associated with increase in the odds of IHD by a factor of 1.21 (95\% CI 1.04 and 1.42). A unit increase in optimism score is associated with decrease in the odds of IHD by a factor of 0.67 (95\% CI 0.53 and 0.83$)$.

Table 3

Social Variables Independently Associated with IHD

\begin{tabular}{|c|c|c|}
\hline Variable & $\begin{array}{c}\mathrm{B} \\
(S E)\end{array}$ & $\begin{array}{c}\operatorname{Exp}(\mathrm{B}) \\
O R(95 \% \mathrm{CI})\end{array}$ \\
\hline Final model & $3.94 * * *$ & \\
\hline Constant & $(0.79)$ & \\
\hline Social support & $\begin{array}{c}-0.08 * * * \\
(0.01)\end{array}$ & $0.91(0.89-0.95)$ \\
\hline
\end{tabular}

A Binary logistic regression analysis was performed to ascertain social factors associated with IHD in women by using forward conditional method, with IHD as the DV and social variables (family income, education, social support and dominance) as predictor variables. A total of 158 cases were analyzed and the full model significantly predicted presence of IHD (Omnibus Chi-square $=50.97, d f=1, p<.001$ ). The model accounted for between $27 \%$ and $38 \%$ of variance in IHD. Overall $79.1 \%$ of the predictions were accurate. Among the social factors; social support was found to be the only significant protective predictor of IHD. The values of the coefficients revealed that each unit increases in score of social support is associated with decrease in odds of IHD by a factor of 0.91 (95\% CI 0.89 and 0.95 ). Social support turned out to be a significant protective predictor of IHD in women.

\section{Discussion and Conclusion}

In Pakistan, limited research data exists for psychosocial risk factors of IHD. The biomedical community is still hesitant to acknowledge the scientific truth that these factors play a greater, if not equal, role in explaining the IHD etiology (Rosengren et al., 2004). Critical psychosocial risk factors vary considerably between different populations especially due to ethnic diversity; hence it would not be erroneous to assume that these risk factors can be altered for Pakistani population. An extremely enlightening finding of this study was that within Pakistani women trait anger turned out to be a significant psychological risk factor of IHD.

This study finding is inconsistent with available generic empirical findings, internationally; evidence exists confirming that anger is a risk factor for IHD in men, not women (Chida \& Steptoe, 2009; Miller, Smith, Turner, Guijarro, \& Haller, 1996; Strike \& Steptoe, 2004). Moreover, "Healthy Women Study" provides substantial evidence that trait anger is associated with the progression of subclinical carotid, as well as the risk of IHD in women (Räikkönen, Matthews, Flory, Owens, \& Gump, 2004). Spielberger et al. (1985) has documented a strong association between trait and suppressed anger in women as compared to men and suppressed anger has found to be more toxic to health as compared to forcible expression of anger (Dembroski, MacDougall, Williams, Haney, \& Blumenthal, 1985; Harburg, Julius, Kaciroti, Gleiberman, \& Schork, 2003). Suppressed anger has 
Psychosocial factors as predictors of early onset ischemic heart disease in a sample of Pakistani women

found to be associated with IHD mortality in women (Harburg et al., 2003).

Women in our culture suppress negative emotions including anger due to the fact that expression of these emotions is not culturally and religiously acceptable; therefore suppressed anger that strongly associates with trait anger turned out to be a significant risk factor for IHD in indigenous women. However there is no direct empirical evidence from national research supporting or refuting this particular finding that trait anger is a risk factor for IHD in Pakistani women. Thus this study finding warrants attention of researchers from national community to further explore this psychological risk factor of IHD within the women population.

Trait anger was found to be the only significant risk factors of IHD in Pakistani women, whereas optimism and social support were found to be significant protective predictors of IHD. Optimism has found to play a protective role in the onset of IHD. Optimistic explanatory style protects against risk of IHD (Dykema, Bergbower, \& Peterson, 1995; Kubzansky et al., 2001). Tindle et al. (2009) in their study confirmed a reduced risk of MI as well as mortality in women as compared to men who scored higher on dispositional optimism. Likewise, in another study conducted on optimism, researchers documented that optimism was related to a reduced amount of carotid intima-media thickness (IMT) progression over a period of three years, in women (Matthews, Raikkonen, Sutton-Tyrrell, \& Kuller, 2004).

Social support was found to be a significant protective social factor of IHD in Pakistani women. Results of the current study are in line with research conducted internationally: availability of social support has found to act as a protective factor for IHD (Barefoot, Gronbaek, Jensen, Schnohr, \& Prescott, 2005; Uchino, 2004). It appears as if Pakistani culture and religion helps to facilitate close contacts with family and friends; contacts with parents, children, family members, and friends have found to be negatively associated with mortality and IHD incidence (Barefoot et al., 2005). Social cohesiveness has found to be associated with low risk of developing heart disease (Berkman \& Glass, 2000). It is important to note that in spite of the impeding wave of industrialization in Pakistan, our family system and social cohesiveness still remains intact.

Social cohesiveness, larger social networks as well as more frequent social contacts are promoted by the predominantly prevailing Islamic values and cultural orientation. In Pakistan, marriage is a strong source of social support, and the same stands fairly well supported by the research findings that there is a significant negative association of marriage with the risk of cardiovascular morbidity and all causes of mortality (Chandra, 1983; Eaker, Pinsky, \& Castelli, 1992). Perceived stress, anxiety and depression were not found to be significant psychological risk factors of IHD. Although global empirical evidence confirms significant association of IHD with negative factors, namely stress (Strike \& Steptoe, 2004), depression (Barefoot \& Schroll, 1996) and anxiety (Kubzansky \& Kawachi, 2000; Smith \& Ruiz, 2002). Varied reasons can be attributed to the fact that these negative psychological factors did not turn out to be significantly associated with the risk of IHD within women.

In Pakistan, people live in cohesive and well integrated social structures and enjoy the luxuries and support of living in joint family systems. The social and religious structure of Pakistani society tends to provide greater social support and comfort to its inhabitants. The availability of social support has found to modify the negative impact of stressors and stress (Cobb, 1976; Wills, 1990). Moreover, anxiety and depression are potential reactions to stress (Suls \& Bunde, 2005); hence, availability of greater social support plays an integral role in reducing anxiety and depression along with stress. Family ties and social interactions have been, reportedly, found to lower the level of stress, enhance stress coping behavior and improve psychological health (Wamboldt \& Wamboldt, 2000).

Moreover, hostility was not found to be a significant risk factor of IHD in women. This study findings parallel findings from available literature from international studies, that have documented hostility to be significantly associated with risk of IHD in men (Consedine, Magai, \& Chin, 2004). In addition locus of control did not turn out to be a significant protective factor of IHD in women. This finding is consistent with the existing research evidence available in this regard from studies carried out internationally confirming that woman, as compared to men, have less control in interpersonal relationships and over other life events (Sherman, Higgs, \& 
Rafique, R. \& Amjab, N.

Williams, 1997). Pakistani men as compared to women are domineering and enjoy more control over every sphere of life i.e. social, familial etc.

Moreover, women within our culture differ in their beliefs and attitudes about sense of control as compared to men. Pakistani men dominate the society and usually tend to exert primary control, they try to rectify, change or even fight adverse situations at hand. Women, on the contrary, seem to endorse secondary control and try to adjust according to the situations at hand and usually surrender things to the "will of God". In short, men seem to exert primary control unlike women who have secondary control. Secondary control is related to lower locus of control (Rothbaum, Weisz, \& Snyder, 1982), and can be attributed as a reason as to why locus of control didn't turn out to be a significant protective factor for IHD in women.

Social dominance as a risk factor of IHD has gained attention of researchers in recent years, and is considered as an emerging psychosocial risk factor for IHD (Smith \& Ruiz, 2002). This emerging social factor did not turn out to be a significant risk factor for IHD in women. This finding is inconsistent with available empirical evidence, prospective research has supported a strong association of social dominance with IHD and all cause mortality related to IHD (Houston, Babyak, Chesney, Black, \& Ragland, 1997; Siegman et al., 2000a). Primarily, studies that have assessed questionnaire-based social dominance and its association with IHD did not find an association of dominance with IHD. Rather, these researchers have found a significant association of social dominance with serum triglyceride concentration (Fowkes et al., 1992), level of total serum cholesterol in people with low levels of physical fitness (Greene, Houston, \& Holleran, 1995), and with cardiovascular reactivity (CVR) (Smith et al., 2004).

The information obtained from the process of the available research literature, the only research that has prospectively assessed questionnaire-based social dominance by MMPI 2, and has derived dominance score and its association with CHD has mainly recruited an older sample of men having a mean age of 61 years (Siegman, et al., 2000b). Mean age of the current study sample of women was 46 years. As there is no empirical evidence in the context of social dominance as a risk factor of IHD for our indigenous population, more research evidence is needed to explore the association of self-reported social dominance with risk of IHD so to draw conclusive evidence in this regard.

Furthermore higher family income and more years of education did not turn out to be significant protective social factors of IHD in women. These findings are inconsistent with available literature that strongly supports that higher level of income and greater years of education act as protective factors of IHD (Huisman et al., 2005; Lynch \& Kaplan, 2000). In Pakistan, education and income alone do not lead to better health-related behaviors in women, as these behaviors are usually determined and mainly regulated by the male family members. Major decisions related to health behaviors as well as other life style decisions are usually not under the control of women even if they are educated and belong to a family having higher monthly family income, hence non significant protective effects of education and income for Pakistani women can best be explained while operating within the socio-cultural framework. 


\section{References:}

Banville, D., Desrosiers, P., \& Genet-Volet, Y. (2000). Translating questionnaires and inventories using a cross-cultural translation technique. Journal of Teaching in Physical Education, 19(3), 374-387.

Barefoot, J. C., \& Schroll, M. (1996). Symptoms of depression, acute myocardial infarction, and total mortality in a community sample. Circulation, 93, 1976-1980. Retrieved from http://circ.ahajournals.org/cgi/content/abstract/93/11/1976

Barefoot, J. C., Gronbaek, M., Jensen, G., Schnohr, P., \& Prescott, E. (2005). Social network diversity and risks of ischemic heart disease and total mortality: Findings from the Copenhagen City Heart Study. American Journal of Epidemiology, 161, 960-967. <http://dx.doi.org/10.1093/aje/kwi128>

Bedford, A., \& Foulds, G. A. (1978). Manual of the Personality Deviance scales. Windsor: NFER-Nelson.

Berkman, L. F. \& Glass, T. (2000). Social integration, social network, social support and health. In L. F. Berkman, \& I. Kawashi (Eds.), Social epidemiology (pp. 137-173). New York: Oxford University Press.

Brotman, D. J., Golden, S. H., \& Wittstein, I. S. (2007). The cardiovascular toll of stress. Lancet, 370(9592), 1089-1100. <http://dx.doi.org/10.1016/S0140-6736(07)61305-1>

Chandra, V. (1983). The impact of marital status on survival after an acute myocardial infarction: A population-based study. American Journal of Epidemiology, 117, 320-325.

Chida, Y., \& Steptoe, A. (2009). The association of anger and hostility with future coronary heart disease: a meta-analytic review of prospective evidence. Journal of American College of Cardiology, 53, 936-46. $<$ http://dx.doi.org/10.1016/j.jacc.2008.11.044>

Cobb, S. (1976). Social support as a moderator of life stress. Psychosomatic Medicine, 38, 300-314.

Cohen, S., Kamarck, T., \& Mermelstein, R. (1983). A global measure of perceived stress. Journal of Health and Social Behavior, 24(4), 386-396. <http://dx.doi.org/10.2307/2136404>

Consedine, N. S., Magai, C., \& Chin, S. (2004). Hostility and anxiety differentially predict cardiovascular disease in men and women. Sex Roles, 50(1-2), 63-75. <http://dx.doi.org/10.1023/B:SERS.0000011073.44105.6f >

Dembroski, T. M., MacDougall, J. M., Williams, R. B., Haney, T. L., \& Blumenthal, J. A. (1985). Components of Type A, hostility, and anger-in: Relationship to angiographic findings. Psychosomatic Medicine, 47(3), 219-233.

Dykema, J., Bergbower, K., \& Peterson, C. (1995). Pessimistic explanatory style, stress, and illness. Journal of Social and Clinical Psychology, 14, 357-377. <http://dx.doi.org/10.1521/jscp.1995.14.4.357>

Eaker, E. D., Pinsky, J., \& Castelli, W. P. (1992). Myocardial infarction and coronary death among women: Psychosocial predictions from a 20 year follow up of the women in the Framingham Study. American Journal of Epidemiology, 135, 854-864.

Fowkes, F. G., Leng, G. C., Donnan, P. T., Deary, I. J., Riemersma, R. A., Housley, E. (1992). Serum cholesterol, triglycerides, and aggression in the general population. Lancet, 340(8826), 995-998. $<$ http://dx.doi.org/10.1016/0140-6736(92)93009-C>

Greene, R. E., Houston, B. K., \& Holleran, S. A. (1995). Aggressiveness, dominance, developmental factors, and serum cholesterol level in college males. Journal of Behavioral Medicine, 18, 569-580. $<$ http://dx.doi.org/10.1007/BF01857896>

Harburg, E., Julius, M., Kaciroti, N., Gleiberman, L., \& Schork, M. A. (2003). Expressive/suppressive anger-coping responses, gender, and types of mortality: A 17-year follow-up (Tecumseh, Michigan, 1971-1988). Psychosomatic Medicine, 65(4), 588-597. $<$ http://dx.doi.org/10.1097/01.PSY.0000075974.19706.3B>

Houston, B. K., Babyak, M. A., Chesney, M. A., Black, G., \& Ragland, D. R. (1997). Social dominance and 22-year all-cause mortality in men. Psychosomatic Medicine, 59, 5-12.

Huisman, M., Kunst, A. E., Bopp, M., Borgan, J. K., Borrell, C., Costa, G., .. Mackenbach, J. P. (2005).

Educational inequalities in cause-specific mortality in middle-aged and older men and women in eight 
western European populations. Lancet, 365(9458), 493-500.

Krantz, D. S., \& McCeney, K. T. (2002). Effects of psychological and social factors on organic disease: A critical assessment of research on coronary heart disease. Annual Review of Psychology, 53, 341-369. $<$ http://dx.doi.org/10.1146/annurev.psych.53.100901.135208>

Kubzansky, L. D., \& Kawachi, I. (2000). Going to the heart of the matter: Do negative emotions cause coronary heart disease? Journal of Psychosomatic Research, 48, 323-337. $<$ http://dx.doi.org/10.1016/S0022-3999(99)00091-4>

Kubzansky, L. D., Sparrow, D., Vokonas, P., \& Kawachi, I. (2001). Is the glass half empty or half full? A prospective study of optimism and coronary heart disease in the normative aging study. Psychosomatic Medicine, 63, 910-916.

Lynch, J., \& Kaplan, G. A. (2000). Socioeconomic position. In L. F. Berkman, \& I Kawachi (Eds.), Social epidemiology (pp. 13-35). New York: Oxford University Press.

Matthews, K. A., Raikkonen, K., Sutton-Tyrrell, K., \& Kuller, L. H. (2004). Optimistic attitudes protect against progression of carotid atherosclerosis in healthy middle-aged women. Psychosomatic Medicine, 66, 640-644. <http://dx.doi.org/10.1097/01.psy.0000139999.99756.a5>

Miller, T. Q., Smith, T. W., Turner, C. W., Guijarro, M. L., \& Haller, A. J. (1996). A meta-analytic review of research on hostility and physical health. Psychological Bulletin, 119, 322-348. <http://dx.doi.org/10.1037/0033-2909.119.2.322>

Radloff, L. S. (1977). The CES-D scale: A self-report depression scale for research in the general population. Applied Psychological Measurement, 1(3), 385-401. <http://dx.doi.org/10.1177/014662167700100306>

Räikkönen, K., Matthews, K. A., Flory, J. D., Owens, J. F., \& Gump, B. B. (1995). Effects of optimism, pessimism, and trait anxiety on ambulatory blood pressure and mood during everyday life. Journal of Personality and Socical Psychology, 76(1), 104-113.

Rosengren, A., Hawken, S., Ounpuu, S., Sliwa, K., Zubaid, M., Almahmeed, W.A., .. Yusuf, S. (2004). Association of psychosocial risk factors with risk of acute myocardial infarction in 11,119 cases and 13,648 controls from 52 countries (The INTERHEART Study): Case-control study. Lancet, 364(9437), 953-962. <http://dx.doi.org/10.1016/S0140-6736(04)17019-0>

Rothbaum, F., Weisz, J. R., \& Snyder, S. S. (1982). Changing the world and changing the self: A two-process model of perceived control. Journal of Personality and Social Psychology, 42(1), 5-37. $<$ http://dx.doi.org/10.1037/0022-3514.42.1.5>

Rozanski, A., Blumenthal, A. J., Davidson, W. K., Saab, P. G., \& Kubzansky, L. (2005). The epidemiology, pathophysiology, and management of psychosocial risk factors in cardiac practice: The emerging field of behavioral cardiology. Journal of American College of Cardiology, 45, 637-651.

Rozanski, A., Blumenthal, J. A., \& Kaplan, J. (1999). Impact of psychological factors on the pathogenesis of cardiovascular disease and implications for therapy. Circulation, 99(16), 2192-2217. $<$ http://dx.doi.org/10.1016/j.jacc.2004.12.005>

Scheier, M. F., Carver, C. S., \& Bridges, M. W. (1994). Distinguishing optimism from neuroticism (and trait anxiety, self-mastery, and self-esteem): A reevaluation of the Life Orientation Test. Journal of Personality and Social Psychology, 67, 1063-1078. < http://dx.doi.org/10.1037/0022-3514.67.6.1063>

Sherman, A. C., Higgs, G. E., \& Williams, R. L. (1997). Gender differences in the locus of control construct. Psychology and Health, 12(2), 239-248. <http://dx.doi.org/10.1080/08870449708407402>

Siegman, A. W., Kubzansky, L. D., Kawachi, I., Boyle, S., Vokonas, P. S., \& Sparrow, D. (2000a). A prospective study of dominance and coronary heart disease in the normative aging study. American Journal of Cardiology, 86, 145-149. <http://dx.doi.org/10.1016/S0002-9149(00)00850-X>

Siegman, A. W., Townsend, S. T., Civelek, A. C., \& Blumenthal, S. (2000b). Antagonistic behavior, dominance, hostility, and coronary heart disease. Psychosomatic Medicine, 62, 248-257.

Smith, T. W., Glazer, K., Ruiz, J. M., \& Gallo, L., C. (2004). Hostility, anger, aggressiveness, and coronary heart disease: An interpersonal perspective on personality, emotion, and health. Journal of Personality, 72, 1217-1270. <http://dx.doi.org/10.1111/j.1467-6494.2004.00296.x>

Spielberger, C. D. (1983). Manual for the State-Trait Anxiety Inventory (Revised). Palo Alto, CA: Consulting 
Psychologists Press.

Spielberger, C. D., Johnson, E., Russell, S., Crane, R., Jacobs, G., \& Worden, T. (1985). The experience and expression of anger: construction and validation of an anger expression scale. In M. A. Chesney, \& R. H. Rosenman (Eds.), Anger and hostility in cardiovascular and behavioral disorders (pp. 5-30). New York: McGraw Hill.

Spielberger, C. D. (1999). The State-Trait Anger Expression Inventory-2 (STAXI-2): Professional manual. Odessa, FL: Psychological Assessment Resources.

Strike, P. C., \& Steptoe, A. (2004). Psychosocial factors in the development of coronary artery disease. Progressive Cardiovascular Disorder. 46, 337-347. <http://dx.doi.org/10.1016/j.pcad.2003.09.001>

Suls, J., \& Bunde, J. (2005). Anger, anxiety, and depression as risk factors for cardiovascular disease: The problems and implications of overlapping affective dispositions. Psychological Bulletin, 131, 260-300. <http://dx.doi.org/10.1037/0033-2909.131.2.260>

Tindle, H. A., Chang, Y., Kuller, L. H., Manson, J. E., Robinson, J. G., Rosal, M. C., .. Matthews, K. A. (2009). Optimism, cynical hostility, and incident coronary heart disease and mortality in the Women's Health Initiative. Circulation, 120, 656-62. <http://dx.doi.org/10.1161/CIRCULATIONAHA.108.827642>

Uchino, B. N. (2004). Social support and physical health: Understanding the health consequences of our relationships. New Haven, CT: Yale University Press.

Vallerand, R. J. (1989) Toward a methodology of cross-cultural validation of psychological questionnaires: Implications for research in French. Psychologies Canadians, 30, 662-680.

Wamboldt, M. Z., \& Wamboldt, F. S. (2000). Role of the family in the onset and outcome of childhood disorders: selected research findings. Journal of the American Academy of Child and Adolescent Psychiatry, 39(10), 1212-1219. <http://dx.doi.org/10.1097/00004583-200010000-00006>

Wang, H. X., Mittleman, M. A., \& Orth-Gomer, K. (2005). Influence of social support on progression f coronary artery disease in women. Social Science and Medicine, 60, 599-607. $<$ http://dx.doi.org/10.1016/j.socscimed.2004.05.021>

Wills, T. A. (1990). Social support and the famssily. In E. A. Blechman (Ed.), Emotions and the family: For better or for worse (pp. 75-98). Hillsdale, NJ: Lawrence Erlbaum Associates.

Yusuf, S., Hawken, S., Ounpuu, S., Dans, T., Avezum, A., Lanas, F., ... Lisheng, L. (2004). Effect of potentially modifiable risk factors associated with myocardial infarction in 52 countries (the INTERHEART study): Case-control study. Lancet, 364, 937-952. <http://dx.doi.org/10.1016/S0140-6736(04)17018-9>

Zimet, G. D., Dahlem, N. W., Zimet, S. G. \& Farley, G. K. (1988). The multidimensional scale of perceived social support. Journal of Personality Assessment, 52, 30-41.

$<$ http://dx.doi.org/10.1207/s15327752jpa5201_2 > 
Rafique, R. \& Amjab, N. 